\title{
TEST OF COPPER WIRE DOSE EFFECTIVENESS ON LARVAL MORTALITY OF Aedes Aegypti MOSQUITO IN 2015
}

\author{
Pristiana Rahayu, Winarko, Siti Surasri
}

\begin{abstract}
Control of Aedes aegypti mosquito population still leaves problem that needs to be addressed. The use of copper wire as an alternative of larvicide has been studied yet it has not shown a satisfactory result.

This is study pure experimental research using research design post test only control group design with larvae of Aedes aegypti third instar as samples. Methods of data analysis were descriptive analysis and analytical analysis.

Experiment result shows that based on the success criteria for effective control and safe for health, this research has not found an effective dose of copper wire to kill larvae of Aedes aegypti mosquito that is safe for health for the percentage of larval mortality with concentration of $38.7 \%$ Cu was still below 2 ppm.

It is recommended that governments and communities use and promote copper wire as an alternative larvicide for vector eradication of dengue with predetermined limit of use that is safe for health. Further research can be also carried out with media source of water and variety of concentration.
\end{abstract}

\section{Keywords : Copper wire, Larvae of Aedes aegypti}

\section{PENDAHULUAN}

Demam Berdarah Dengue merupakan salah satu masalah kesehatan yang penting dan utama bagi negara-negara tropis termasuk Indonesia. Menurut metode yang dikembangkan oleh WHO untuk memerangi penyakit demam berdarah sama seperti metode yang digunakan untuk memerangi penyakit malaria yaitu dengan membasmi sumber penularannya yaitu larva nyamuk (Manuel, 1992 dalamI W. Suirtadkk, 2009) Pembasmian larva nyamuk Aedes aegypti sebagai upaya pemutusan siklus hidup nyamuk Aedes aegypti pada tempat perindukan umumnya dilakukan dengan menguras bak mandi, menutup tempat yang mungkin menjadi tempat berkembang biaknya nyamuk, mengubur barang bekas yang dapat menampung air dan menggunakan bubuk abate.

Penggunaan bubuk abate tidak sepenuhnya bisa diandalkan karena jarang dilakukan secara mandiri. Selain itu dapat menyebabkan dinding tempat penampungan air terlihat kotor karena terselimuti oleh bubuk abate yang menempel. Menurut Komisi Pestisida (1995) dalam Siti Alfiah dan Riyani Setiyaningsih (2012) kriteria pengendalian dikatakan efektif apabila persentase kematian larva uji yang dihasilkan > $90 \%$.

Secara teori menurut Heryando Palar (2004) logam-logam berat yang terlarut dalam badan perairan pada konsentrasi tertentu akan menjadi sumber racun bagi kehidupan perairan. Dan salah satu logam berat yang penting bagi organism namun dapat mengakibatkan kematian apabila masuk dalam tubuh dengan jumlah yang berlebihan adalah tembaga (Cu). Seiring dengan berkembangnya perindustrian di Indonesia, tembaga (Cu) telah banyak digunakan secara luas sebagai bahan baku produksi. Misalnya dalam bidang perlistrikan seperti kabel listrik.Selain itu tembaga juga dapat dimanfaatkan dalam industri cat, industri insektisida dan fungisida. (Heryando Palar, 2004:64)

Pada uji laboratorium yang telah dilakukan oleh Roberto Romi dkk (2000) diketahui bahwa pemberian kawat tembaga di dalam tempat penampungan air berpengaruh pada pertumbuhan larva nyamuk Aedes albopictus. Pada percobaan tersebut, dosis 10 gram per liter terjadi kematian larva yang tinggi sedangkan pada dosis 20 gram per liter larva sepenuhnya terhambat karena larva mati secara total. Sedangkan penelitian yang dilakukan oleh Siti Surasri dkk (2014) diketahui bahwa pemberian kawat tembaga di dalam tempat penampungan air dengan dosis 1,25 gram per liter air mampu menghambat pertumbuhan larva nyamuk Aedes aegypti.

Penggunaan kawat tembaga apabila dibandingkan dengan penggunaan bubuk abate, relatif lebih mudah didapatkan dan 
mudah mengaplikasikannya. Di sisi lain, penggunaan kawat tembaga tidak menyebabkan dinding tempat penampungan air menjadi kotor dan tidak bersifat toksik pada penggunanya karena kadar tembaga yang larut ke dalam air sangat rendah. Dimana WHO telah menetapkan bahwa batas aman kadar tembaga yang

Larut ke dalam air maksimal adalah 2ppm (Guidelines, 2004 dalam SitiSurasri, 2014) sehingga aman bagi kesehatan.

Penelitian ini bertujuan untuk menentukan dosis kawat tembaga yang efektif terhadap kematian larva nyamuk Aedes aegypti.

\section{METODE PENELITIAN}

Penelitian ini merupakan eksperimen murni dengan rancangan bangun post test only control group design, sedangkan sampel penelitian adalah larva nyamuk Aedes aegypti instar tiga. Penelitian ini menggunakan variasi dosis kawat tembaga dan kontrol serta dilakukan pengulangan sebanyak 5 kali untuk setiap variasi dosis termasuk kontrol sehingga besarnya sampel penelitian yang digunakan sebanyak 30 sampel. Variabel bebas penelitian adalah variasi dosis kawat tembaga, variabel terikat adalah jumlah larva nyamuk Aedes aegypti yang mati dan variabel pengaruh adalah kelarutan $\mathrm{Cu}$ di dalam air. Data diperoleh dari observasi langsung larva nyamuk Aedes aegypti yang mati setiap 24 jam selama 8 hari pada masing - masing pengulangan di setiap kontainer. Data yang sudah terkumpul diolah dan disusun dalam bentuk tabel kemudian dianalisis secara analitik.

HASIL PENELITIAN DAN PEMBAHASAN

Perbedaan Kematian Larva Nyamuk Aedes aegypti Pada Berbagai Dosis Kawat Tembaga

Tabel 1.

Kematian larva nyamuk Aedes aegyptipada masing-masing pengulangan menurut berbagai dosis kawat tembaga tahun 2015

\begin{tabular}{|c|c|c|c|c|c|c|c|c|c|}
\hline \multirow[t]{2}{*}{ Kode } & \multirow{2}{*}{$\begin{array}{l}\text { Dosis } \\
\text { (gr/L) }\end{array}$} & \multicolumn{5}{|c|}{$\begin{array}{l}\text { Kematian larva nyamuk } \\
\text { Aedes aegypti pada } \\
\text { pengulangan ke- }\end{array}$} & \multirow{2}{*}{$\begin{array}{l}\text { Kisaran } \\
\text { kematian } \\
\text { (ekor) }\end{array}$} & \multirow{2}{*}{$\begin{array}{l}\text { Jumlah } \\
\text { kematian } \\
\text { (ekor) }\end{array}$} & \multirow{2}{*}{$\begin{array}{l}\text { Persentase } \\
\text { kematian } \\
(\%)\end{array}$} \\
\hline & & I & II & III & IV & V & & & \\
\hline 1 & 0 & 1 & 2 & 0 & 0 & 0 & $0-2$ & 3 & 4 \\
\hline 2 & 1,25 & 0 & 2 & 2 & 0 & 0 & $0-2$ & 4 & 5,3 \\
\hline 3 & 2,5 & 5 & 5 & 2 & 1 & 0 & $0-5$ & 13 & 17,3 \\
\hline 4 & 5 & 1 & 4 & 0 & 3 & 5 & $0-5$ & 13 & 17,3 \\
\hline 5 & 7,5 & 7 & 3 & 2 & 3 & 9 & $2-9$ & 24 & 32 \\
\hline 6 & 10 & 7 & 5 & 7 & 4 & 6 & $4-7$ & 29 & 38,7 \\
\hline
\end{tabular}

Berdasarhasil penelitian menunjukkan bahwa pada dosis $0 \mathrm{gr} / \mathrm{L}$ (kontrol) terdapat kematian larva nyamuk Aedes aegypti sebesar $4 \%$. Hal ini dikarenakan larva nyamuk Aedes aegypti yang digunakan sebagai larva uji diduga mengalami keracunan $\mathrm{Cu}$ yang secara alami telah ada pada media air yang digunakan. Pada hal ini tidak perlu dilakukan koreksi angka kematian menggunakan rumus abbot karena persentase kematian larva uji tidak melebihi $5 \%$.

Kematian larva nyamuk Aedes aegypti paling sedikit pada dosis $1,25 \mathrm{gr} / \mathrm{L}$ sebesar $5,3 \%$. Hal ini sesuai dengan penelitian yang telah dilakukan oleh Siti Surasri dkk (2014) bahwa pemberian kawat tembaga di dalam penampungan air dengan dosis $1,25 \mathrm{gram}$ per liter air telah mampu menghambat pertumbuhan larva nyamuk Aedes aegypti.

Sedangkan kematian larva nyamuk Aedes aegypti terbanyak pada dosis $10 \mathrm{gr} / \mathrm{L}$ sebesar $38,7 \%$. Hal ini dikarenakan dosis kawat tembaga tersebut telah mengalami kelarutan dalam jumlah berlebihan sehingga diduga tidak mampu dimetabolisme oleh tubuh larva nyamuk Aedes aegypti dan menyebabkan kematian larva nyamuk Aedes aegypti dalam jumlah terbanyak.

Hasil tersebut juga dibuktikan dengan Uji Anova yang menunjukkan bahwa nilai $\mathrm{p}=0,001<\mathrm{a}=0,05$. Artinya minimal ada 1 pasang dosis kawat tembaga yang berbeda daya bunuhnya terhadap larva nyamuk Aedes aegypti yaitu antara dosis 1,25 gr/L dengan dosis $7,5 \mathrm{gr} / \mathrm{L}$ atau antara dosis $1,25 \mathrm{gr} / \mathrm{L}$ dengan dosis $10 \mathrm{gr} / \mathrm{L}$. 


\section{Hubungan Dosis Kawat Tembaga Dengan Kelarutan Cu}

Tabel 2.

Kelarutan Cu di dalam air menurut berbagai dosiskawat tembaga tahun 2015

\begin{tabular}{|c|c|c|c|}
\hline Kode & $\begin{array}{c}\text { Dosis } \\
(\mathrm{gr} / \mathrm{L})\end{array}$ & $\begin{array}{c}\text { Hasil pemeriksaan konsentrasi Cu } \\
(\mathrm{mg} / \mathrm{L})\end{array}$ & Kelarutan Cu (mg/L) \\
\hline 1 & 0 & 0,284 & 0 \\
\hline 2 & 1,25 & 0,554 & 0,270 \\
\hline 3 & 2,5 & 0,717 & 0,433 \\
\hline 4 & 5 & 0,811 & 0,527 \\
\hline 5 & 7,5 & 0,991 & 0,707 \\
\hline 6 & 10 & 1,145 & 0,861 \\
\hline
\end{tabular}

Tabel 2. menunjukkan bahwa media pertumbuhan larva nyamuk Aedes aegypti padadosis $0 \mathrm{gr} / \mathrm{L} \quad$ (kontrol) telah mengandung $\mathrm{Cu}$ sebelumnya sebesar 0,284 $\mathrm{mg} / \mathrm{L}$ dan tidak menunjukkan peningkatan dosis $\mathrm{Cu}$, karena tidak diberi penambahan kawat tembaga di dalamnya. Sedangkan media pertumbuhan larva nyamuk Aedes aegypti yang diberi penambahan kawat tembaga di dalamnya dengan berbagai dosis menghasilkan konsentrasi dan kelarutan $\mathrm{Cu}$ yang semakin tinggi sesuai dengan besarnya dosis kawat tembaga yang ditambahkan. Hal ini dibuktikan dengan Uji Korelasi Pearson yang menunjukkan bahwa ada hubungan dosis kawat tembaga dengan kelarutan $\mathrm{Cu}$ di dalam air dengan nilai $\mathrm{p}=$ $0,000<a=0,05$.

Dosis Kawat Tembaga yang Efektif Terhadap Kematian Larva Nyamuk Aedes aegypti Sekaligus Aman Bagi Kesehatan

Tabel 3.

Kematian larva nyamuk Aedes aegypti menurut dosis dan kelarutanCu tahun 2015

\begin{tabular}{|c|c|c|c|c|c|}
\hline Kode & $\begin{array}{c}\text { Dosis } \\
(\mathrm{gr} / \mathrm{L})\end{array}$ & $\begin{array}{c}\text { Hasil pemeriksaan } \\
\text { konsentrasi Cu } \\
(\mathrm{mg} / \mathrm{L})\end{array}$ & $\begin{array}{c}\text { Kelarutan Cu } \\
(\mathrm{mg} / \mathrm{L})\end{array}$ & $\begin{array}{c}\text { Persentase } \\
\text { kelarutan Cu (\%) }\end{array}$ & $\begin{array}{c}\text { Persentase } \\
\text { kematian } \\
(\%)\end{array}$ \\
\hline 1 & 0 & 0,284 & 0 & 0 & 4 \\
\hline 2 & 1,25 & 0,554 & 0,270 & 0,021 & 5,3 \\
\hline 3 & 2,5 & 0,717 & 0,433 & 0,017 & 17,3 \\
\hline 4 & 5 & 0,811 & 0,527 & 0,010 & 17,3 \\
\hline 5 & 7,5 & 0,991 & 0,707 & 0,009 & 32 \\
\hline 6 & 10 & 1,145 & 0,861 & 0,008 & 38,7 \\
\hline
\end{tabular}

Penelitian menunjukkan bahwa dosis $\mathrm{Cu}$ tertinggi $10 \mathrm{gr} / \mathrm{L}$ menghasilkan persentase kematian larva sebesar 38,7 \%. Menurut Komisi Pestisida (1995) dalam Siti Alfiah dan Riyani Setiyaningsih (2012) kriteria pengendalian dikatakan efektif apabila persentase kematian larva uji yang dihasilkan > $90 \%$, sehingga dalam penelitian ini dosis $10 \mathrm{gr} / \mathrm{L}$ masih dikatakan tidak efektif terhadap kematian larva nyamukAedes aegypti karena persentase kematian larva uji kurang dari kriteria yang telah ditetapkan.

Sementara itu, menurut ketetapan WHO batas kadar tembaga maksimal di dalam air adalah 2 ppm (Guidelines, 2004 dalam Siti
Surasri, 2014). Dan berdasarkan tabel IV.4 diketahui juga bahwa dosis tertinggi yaitu 10 gram/L menghasilkan kelarutan $\mathrm{Cu}$ tertinggi namun masih dibawah batas kadar tembaga maksimal di dalam air yang telah ditetapkan, sehingga meskipun dosis tersebut tidak efektif terhadap kematian larva nyamuk Aedes aegypti tetapi masih sangat aman bagi kesehatan karena kelarutan $\mathrm{Cu}$ di dalamnya hanya sebesar $0,086 \mathrm{mg} / \mathrm{L}$.

\section{KESIMPULAN DAN SARAN}

Kesimpulan

Komisi Pestisida (1995) dalam Siti Alfiah dan Riyani Setiyaningsih (2012) menetapkan 
kriteria pengendalian dikatakan efektif apabila persentase kematian larva uji yang dihasilkan $>90 \%$. Sementara itu, menurut ketetapan WHObatas kadar tembaga maksimal di dalam air yang aman bagi kesehatana dalah 2ppm (Guidelines, 2004 dalam Siti Surasri, 2014). Dalam penelitian ini belum didapatkan dosis kawat tembaga yang efektif terhadap kematian larva nyamuk Aedes aegypti tetapi masih aman bagi kesehatan. Hal ini dibuktikan dari persentase kematian larva nyamuk Aedes aegypti dibawah kriteria yang telah ditetapkan yaitu 38,7 \% dan konsentrasi $\mathrm{Cu}$ yang dihasilkan hanya sebesar 1,145 $\mathrm{mg} / \mathrm{L}$.

Saran

1. Bagi Pemerintah dan masyarakat dapat menggunakan sekaligus mempromosikan kawat tembaga sebagai alternatif larvasida untuk pemberantasan vektor DBD dengan penggunaannya yang tidak melebihi batas yang telah ditetapkan agar aman bagi kesehatan.

2. Bagi peneliti lain, dapat melakukan penelitian lebih lanjut mengenai kemampuan berbagai dosis kawat tembaga dengan memperhatikan sumber air media dan berbagai konsentrasinya.

\section{DAFTAR PUSTAKA}

Alfiah, Siti dan Riyani Setiyaningsih, 2012. Efikasi Larvasida Berbahan Aktif Benzoyl Phenil Urea Sebagai Insect Growth Regulator Terhadap Larva Culex quinquefasciatus Di Laboratorium. Jurnal Vektor Dan Reservoir Penyakit, 1 (4) : 45-50.

Aradilla, Ashry Sikka, 2009. Uji Efektivitas Larvasida Ekstrak Ethanol Daun Mimba (Azadirachta indica) terhadap Larva Aedes

aegypti.http://eprints.undip.ac.id/8088 L1/Ashry Sikka.pdf. diakses pada tanggal 14 Januari 2015 pukul 10.20 WIB.

Chandra, Budiman. 2011. Kontrol Penyakit Menular Pada Manusia. Jakarta: Buku Kedokteran EGC.

Depkes RI. 2005. Pemberantasan Nyamuk Penular Demam Berdarah Denque.Jakarta: Ditjen PPM \& PLP.

Ikwi Wijaya Novianto, 2007. Kemampuan Hidup Larva Culex quinquefasciatus Say. pada Habitat Limbah Cair Rumah Tangga.http://eprints.uns.ac.id/3217/1 55831106200909571.pdf. diakses pada tanggal 13 Januari 2015 pukul $\underline{14.00 \mathrm{WIB} .}$
Islamiyah, Siti Nurul dan Toeti Koestiari, 2014. Analisis Kadar Logam Tembaga (II) di Air Laut Kenjeran. http://fmipa.unesa.ac.id/kimia/wpcont ent/uploads/2013/11/27-31-Siti-Nurulislamiya h-baru.pdf. diakses padatangqal 22 Desember 2014pukul 11.00 WIB.

Mading, Majematang, 2013. Fauna dan Karakteristik Tempat Perkembangbiakan Nyamuk Anopheles sp. di Desa Selong Belanak Kabupaten Lombok

Tengah.http://ejournal.litbang.depkes. go.id/index.php/ipbb/article/download/ 3275/321. diakses pada tanggal 22 Desember 2014pukul 15.30 WIB.

Maria, Ita, Hasanuddin Ishak, dan Makmur Selomo, 2013. Faktor Risiko Kejadian Demam Berdarah Dengue (DBD) di Kota Makassar. http://repository.Unhas.ac.id/bitstream Lhandle/123456789/5820/ita\%20maria faktor\%20risiko\%20kejadian.pdf?seq uence $=1$. diakses pada tanggal 22 Desember 2014pukul 08.10 WIB.

Nasronudin. 2007. Penyakit Infeksi Di Indonesia. Surabaya: Airlangga University Press.

Notoatmodjo, Soekidjo. 2012. Metodologi Penelitian Kesehatan. Jakarta: Rineka Cipta.

Palar, Heryando, 2004. Pencemaran \& Toksikologi Logam Berat. Jakarta: PT Rineka Cipta : 37-67.

Ridha, MR., dkk, 2013. Hubungan Kondisi Lingkungan dan Kontainer dengan Keberadaan Jentik Nyamuk Aedes aegypti di Daerah Endemis Demam Berdarah Dengue di Kota Banjarbaru, http://ejournal.litbang.depkes.go.id/in dex.php/buski/article/download/3231/ 3202.diakses pada tanggal 14 Januari 2015pukul 16.00 WIB.

Romi, Roberto dkk, 2000. Laboratory and Field Evaluation of Metallic Copper on Aedes albopictus (Diptera: Culicidae) Larval

Development.http://dx.doi.org/10.160 3/0022-258537.2.281._diakses padatanggal14 Desember 2014pukul 19.15 WIB.

Rosa, Emantis, 2007. Studi Tempat Perindukan Nyamuk Vektor Demam Berdarah Dengue di dalam dan di luar rumah di Rajabasa Bandar Lampung.http://jurnal.fmipa.unila.ac.i d/index.php/sains/article/download/14 6/pdf. diakses pada tanggal 14 Desember 2014pukul 08.25 WIB. 
Santoso, Fitri, 2011. Analisis Faktor yang Berhubungan dengan Kejadian

Chikungunya di Wilayah Kerja Puskesmas Gunungpati Kota Semarang.

http://lib.unnes.ac.id/7989/4/8571.pdf. diakses pada tangqal 22 Desember 2014pukul 18.20 WIB.

Sandina, Dewi. 2011. 9 Penyakit Mematikan. Yogyakarta: Smart Pustaka.

Setiyaningsih, Riyani dan Maria Agustini, 2012. Pengaruh Frekuensi Penghisapan Darah terhadap Perkembangan, Reproduksi, Vertilitas, dan Rasio Sex Aedes aegypti. Jurnal Vektor Dan Reservoir Penyakit, 1 (4) : 33-43.

Sucipto, Cecep Dani, 2011. Vektor Penyakit Tropis. Yogyakarta, Gosyen Publishing : 45-59.

Suirta, I W., N. M. Puspawati, dan N. K. Gumiati, 2007. Isolasi dan Identifikasi Senyawa Aktif Larvasida dari Biji Mimba (Azadirachta indika A. Juss) terhadap Larva Nyamuk Demam Berdarah (Aedes aegypti).http://ojs.unud.ac.id/index.ph $\mathrm{p} /$ ichem/article/download/2682/1896. diakses pada tanggal 22 Desember 2014pukul 17.10 WIB.

Sunjaya, Deni Kurniadi dan Dewi Marhaeni Diah Herawati. 2012. Sistem Surveilans Dan Respons. Jakarta: CV Sagung Seto.

Surasri, Siti dkk, 2014. Pemanfaatan kawat tembaga untuk mencegah perkembangan jentik nyamuk pada kontener air dirumah tangga. Surabaya: Poltekkes jurusan Kesehatan Lingkungan.

Surasri, Sitidan Setiawan, 2005. Metodologi Penelitian. Surabaya, Unit PPM Poltekkes Surabaya : 14.

Soegijanto, Soegeng, 2004. Demam Berdarah Denque. Surabaya, Airlangqa University Press : 100-104.

WHO, 2004. Panduan Lengkap Pencegahan \& Pengendalian Dengue \& Demam Berdarah Denque. Jakarta, Buku Kedokteran EGC : 60-61.

Widoyono, 2008. PENYAKIT TROPIS Epidemiologi, Penularan, Pencegahan \& Pemberantasannya. Jakarta, Erlangga : 60. 